\title{
CROSS-SECTIONAL ANALYSIS OF THE METHODS USED TO EVALUATE THE MENTAL AND PHYSICAL WELL BEING OF MILITARY PERSONNEL
}

\author{
Gabriela Kloudova $^{1}$, Vaclav Gerla ${ }^{2}$, Kristyna Rusnakova ${ }^{1}$, Radim Belobradek, \\ \& Miloslav Stehlik ${ }^{1}$ \\ ${ }^{1}$ Sport Research Institute of Czech Armed Forces (Czech Republic) \\ ${ }^{2}$ Czech Institute of Informatics, Robotics, and Cybernetics, Czech Technical University in Prague \\ (Czech Republic)
}

\begin{abstract}
Military service is both physically and mentally demanding given its risk factors, shift work, long working hours, the necessity of relocation and great responsibility. Although soldiers are highly selected from among the population, their daily duties can be reflected in their health. In this study, we chose two specific military groups that have very different tasks in the Czech Army to determine their actual physical and mental states. The first group was the military Castle Guard, and the second group was military paratroopers. Both of these groups underwent psychological testing of personality, IQ, self-evaluation, cognitive abilities and the motivation to perform the duties of military service. Physical health was tested by a body composition analysis, health-related biochemical parameters, sleep analysis and diagnostics on the musculoskeletal apparatus. The aim of our study was to find significant associations that have an impact on the well-being of elite Czech military units, and for this purpose we used the association rule learning method. The results of this study demonstrate the most significant associations between the mental state of soldiers and their quality of sleep. The health state was usually reflected in the sleep pattern which plays a role in life vitality, independence and professional success. The results support the need for the complex preparation of military personnel and a much-needed prevention program which would also include sleep adjustments that would help to improve their overall performance and to maintain appropriate combat readiness.
\end{abstract}

Keywords: Physical and mental workload analysis, military castle guard, military paratroopers, combat readiness.

\section{Introduction}

Military personnel are confronted daily with mental and physiological challenges given by a difficult working environment defined by its rules, responsibility and discipline. To perform well in these conditions, it is necessary to consider both mental and physical well-being within a single context. This study aims to reveal the current state of the Czech Army in the very different, but both highly responsible, aspects and to see which components play the main role in their well-being. Since the Czech Army is fully professional and it's more and more difficult to find competent personnel, it is important to help current soldiers keep fit. Due to the discrepancy between the requirements for military personnel and their actual physical abilities, a risk of chronic disability may occur (Larsson, Tegem \& Harms-Ringdahl, 2012; Payne \& Harvey, 2010).

This broad-spectrum study was designed to verify the mental and physical states of military units. Soldiers regularly undergo psychological testing which is utilized in describing, explaining, predicting and modifying behaviors (Nwafor \& Adesuwa, 2014). However, to prevent possible problems, it is necessary to include testing for motivation, cognitive ability, self-evaluation and IQ as well to keep performance at the highest level. A high motivation to work in the military and a dedication to the cause can help protect against posttraumatic stress disorder (PTSD) together with better intellectual functioning (Kaplan et al., 2002). Good cognitive abilities are usually a decisive factor in a soldier's tasks, and they should be kept at the highest possible level. Findings indicate that when soldiers are under stress their decision-making and cognitive functioning are significantly decreased, which can also result in lowered shooting accuracy (Nibbeling, Oudejans, Ubink, \& Daanen, 2014). Moreover, it can be associated with additional health concerns, less physical activity, less vitality, and more emotional problems (Zammit, Weiner, Damato, Sillup \& McMillan, 1999). Even one night of sleep deprivation can cause considerable deterioration in alertness and performance, which makes accidents in the workplace more likely (Van Dongen, 2006). Especially in the military environment, sleep can be impaired because of common shift changes. 
Night-shift soldiers have significantly worse sleep efficiency as compared to day-shift soldiers. They also reported more problems falling asleep and staying asleep compared to the day-shift (Peterson, Goodie, Satterfield \& Brim, 2008). Disrupted sleep, as is usually seen in military personnel on duty, results in a high risk of daytime sleepiness and fatigue (Toblin et al., 2012). A sleep deficit decreases combat performance, and there is a significant association between the number of hours of sleep and the incidence of mistakes and potential accidents (loPresti et al., 2016). Unfortunately, among the military, little attention is paid to sleep quality. When taking breaks, the rest areas for soldiers are not customized for healthy sleep, as sleeping areas are usually uncomfortable and noisy (Troxel et al., 2015). Sleep is currently disregarded during operational planning, although it might produce significant advantages in increased readiness and resilience (Mysliwiec, Walter, Collen, \& Wesensten, 2016). In operational planning, the breaks and spare time are not well-organized, so, instead of sleeping, soldiers communicate with their families or play video games (Pruiksma \& Peterson, 2018). Too much excitement before sleep produces insomnia among military personnel (Bonnet \& Arand, 2010; Ramos, Arvelo, \& Gomez, 2013).

The biochemical parameters related to stress and overload are usually cortisol, creatine kinase (CK) and urea. Fatigue is most accurately reflected in urea for endurance activity. On the other hand, for strength training, the best blood-borne marker reflecting fatigue is increasing CK (Hecksteden et al., 2016). Creatine kinase is an enzyme that catalyzes the conversion of creatine to creatine phosphate, which serves as an energy storage in the body. Serum CK increases in healthy subjects right after exercise which consists of a very intense muscular load, and it is probably the best biochemical marker of muscle fiber damage (Mougios, 2019). Urea is formed in the liver, and it is the end product of protein metabolism, it serves as the main product of the excretion of excess nitrogen from the body. After performing long-lasting exercise, there is usually a higher concentration of urea occurring in the blood (Viru \& Viru, 2001). The accumulation of urea does not change during short-term exercise, but it increases with longer-lasting effort and depends primarily on the duration and intensity of exercise (Mougios, 2019). Cortisol is known to be a key factor in the biological stress response, and it mainly contributes to the regulation of stress responses (Glienke \& Piefke, 2017). An increased release of cortisol occurs in a body facing a stressor by up to ten times the normal amount (Lüllmann, Mohr, \& Wehling, 2004). Measuring cortisol at rest can help estimate physical and mental stress, while measuring cortisol after exercise can show the adaptation of the body to a certain stress load level (Mougios, 2019). Exercise based on endurance can cause significant changes in resting cortisol values (Anderson, Lane \& Hackney, 2016). Cortisol secretion is suppressed in sleep, and therefore in long-lasting sleep deprivation, the cortisol level tends to remain higher and can be a marker of chronic insomnia (Basta, Chrousos, Vela-Bueno, \& Vgontzas, 2007). While a number of test batteries and procedures are used in the military to determine physical fitness, muscle strength and endurance, unfortunately they are often not sufficiently relevant or reliable to predict an increased risk of injury or to assess real physical performance (Malmberg, 2011; Larsson, Tegern \& Harms-Ringdahl, 2012). The test of muscle imbalance could be a good indicator of possible future problems, because the number of individuals with muscle imbalance has increased, especially in the lower limbs which are usually caused by incorrect posture or inappropriate lifestyle (Kang et al., 2011).

\section{Subjects}

The subjects tested were from two military groups significantly different in their type of duty. The first group consisted of 105 men working as the Castle Guard, ensuring the protection of the Czech president and other statesmen. The second group consisted of 101 men working as paratroopers (military parachutists) in the Czech Army. Their duty is quite different in physical demands and also in a different sleeping schedule. The airborne gets a full night's sleep, even when on duty, but the Castle Guard sleeps in 2-hour intervals. The schedule is divided into a two-hour duty, a two-hour rest and two-hour preparation for another duty including night shifts. On the other hand, the airborne has much more strenuous physical demands, and there is a greater risk of injuries.

\section{Methods}

To analyze sleep and its impact on the performance of soldiers on duty, we used actigraphy to extract the main actigraphic variables. For this purpose, we used a Mindpax MindG bracelet actigraphic device which is battery-powered unit with a Kionix KX022 accelerometer. Detailed indexes derived from actigraphic data: average sleep time per 24 hour period, time to fall asleep, wake-up time, number of arousals during sleep, sleep efficiency estimate, amount of daily sleep, amount of daily activity, chronotype estimate, percentage and stability estimates of individual sleep stages (deep sleep, light sleep, REM), regularity of wake-up time, speed of fall asleep, etc. These indexes were computed as a mean value over multiple days (2-14 days for individual subjects). AKTI IND features were transferred to 5-point scale where 1 is minimum, 2-3 is average for given population and 5 is maximum. The body composition measurement 
device was a Tanita foot-to-foot and hand-to-foot bioelectrical impedance analyzer. The MC780U Multi Frequency Segmental Body Composition Analyzer was used in this study and provided data on weight, body fat, fat mass, muscle mass, total body water, body mass index, bone mass and basal metabolic rate. Biochemistry data were obtained by a biochemical analysis from a blood sample. For all participants, a capillary blood sample was taken and immediately analyzed using a dry chemistry method (SPOTCHEMTM EZ SP-4430). Further, hormone cortisol was measured in the blood sample by the enzyme-linked immunosorbent assay (ELISA). The muscle endurance test was based on the McGill test (McGill, 1999) protocols divided into four core endurance tests. The subjects were instructed to hold a static position for as long as possible. The endurance tests included the trunk flexor test, the trunk extensor test, and the bilateral side bridge test. Cognitive tests were administered to measure the level of the cognitive performance of the soldiers. The test battery contained the psychomotor vigilance test (PVT), Go/NoGo, visual search, inhibition of return, the Corsi block test and the Mackworth clock task. The tasks assigned are described in more detail in the PsyToolkit SW (Stoet 2010; Stoet 2017). Psychological data were obtained by the NEO-PI-R personality test which can detect the main tendencies for neuroticism, depression, conscientiousness and agreeableness (Costa \& McCrae, 2008). The motivation to work in the military and to perform daily duties was measured by a series of questions covering the weekly schedule of the soldiers, including work, family and leisure balance, and their motivation to make any changes. Another method was mapping the life satisfaction of the soldiers tested using a self-evaluation questionnaire. The task was to evaluate each item on a scale of 1-10 from worse to the best. The test had 10 scales referring to appearance, health, independence, physical fitness, work success rate, sexual performance, ability to satisfy your partner, vitality and life satisfaction. The IQ test used was the Efekt computer-based test which among the usual IQ score provided data about the level of aspiration of the subjects tested based on Kurt Lewin's research (Lewin, 1944). Strategy tells us how the person accurately evaluates his abilities. The points are based on the level of another question he chooses after failure or correctly answered question, so the higher the number is the higher aspirations the person has and takes more risk. Cata feature in the Efekt test means that even after correct answer the person lowers his aspirations and chooses easier question. The Pole feature is about overestimating abilities because the person chooses more difficult question after a failure. All of the last three mentioned tests were specially constructed by CASRI for the purposes of this research project, although their significance among military subjects has already been proven in previous projects conducted by the Czech Armed Forces.

\section{Results}

In this study, we obtained a total of 149 features. We worked with incomplete data, because it was not possible to perform all the necessary experiments on all the subjects analyzed. Features whose missing data rate was above the threshold th $=75 \%$ for at least one dataset were removed and not considered in further analyses. The total number of features after feature rejection was 118 .

We used an apriori-type algorithm for generating the association rules executed in the Weka software (Frank, Hall \& Witten, 2016). The algorithm iteratively reduces the minimum support until it finds the required number of rules with the given minimum confidence. Confidence is computed as the proportion of the examples covered by the premise that are also covered by the consequence. We used a "lift" metric with the minimum of criteria set to 1.1. Lift is confidence divided by the proportion of all examples that are covered by the consequence. This is a measure of the importance of the association that is independent of support.

As typical for association rule learning, the number of rules found is enormous. The total number of association rules found for Castle Guard was 757599, and for paratroopers 307304. The most relevant results are based on the counted only simple rules across different groups with lift $>2$. For Castle Guard the number of rules found was 190 and 20 for paratroopers. In Table 1 and Table 2 are the most significant results for each group regarding the lift parameter. This is a direct output of the Weka software (Frank, Hall \& Witten, 2016).

Table 1. Best rules found for the Castle Guard dataset.

\begin{tabular}{|c|c|}
\hline & 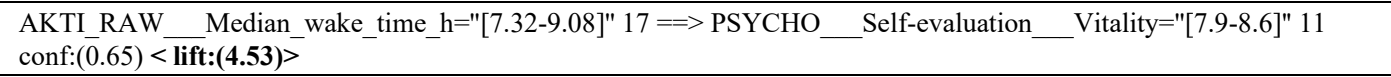 \\
\hline & $\begin{array}{l}\text { PSYCHO_Self-evaluation_Vitality="[7.9-8.6]" } 15=\text { _ AKTI } \\
\text { IND_Continuity_of_sleep_estimated_by_number_of_arousals=" }[2,6-3] \text { " } 12 \text { conf:(0.8) < lift:(3.65)> }\end{array}$ \\
\hline & $\begin{array}{l}\text { AKTI_IND__Continuity_of_sleep_estimated_by_height_of_microarousals="[2.6-3]" } 23==>\text { PSYCHO___Self- } \\
\text { evaluation__ndependence="'[9.5-inf]" } 11 \text { conf:(0.48) < lift:(3.59) }>\end{array}$ \\
\hline & $\begin{array}{l}\text { AKTI_IND__SSleep_efficiency="[2.6-3]" } 23=>\text { PSYCHO__Self-evaluation_Appearance="[6.8-7.2]" } 11 \text { conf:(0.48) < } \\
\text { lift:(3.59)> }\end{array}$ \\
\hline & $\begin{array}{l}\text { PSYCHO_Self-evaluation_Health="[8.5-9]" } 16==>\text { AKTI_IND Average_number_of_arousals="[2.6-3]" 12 conf:(0.75) } \\
<\text { lift:(3.42)> }\end{array}$ \\
\hline
\end{tabular}


Table 2. Best rules found for the paratroopers' dataset.

\begin{tabular}{|ll|}
\hline 1. & KOGNI_CORSI="[40-50]" $13==>$ PSYCHO Self-evaluation_work_success_rate= "[7.9-8.6]" 10 conf:(0.77) <lift:(2.99)> \\
\hline 2. & $\begin{array}{l}\text { AKTI_RAW Dispersion_of_sleep_effectivity_\% }="[1.3-1.95] " 14==>\text { Self evaluation_work_rate_success ="[7.9-8.6]" } 10 \\
\text { conf:(0.71) < lift:(2.77)> }\end{array}$ \\
\hline 3. & $\begin{array}{l}\text { AKTI_RAW_Number_of_awakenings_per_hour_>_10_min="[-inf-0.04]" } 23==>\text { BIO Anthropometry Basal_metabolism_kcal } \\
=\text { "[2097.5-2225.4]" } 10 \text { conf:(0.43) }<\text { lift:(2.31) }>\end{array}$ \\
\hline 4. & $\begin{array}{l}\text { BIO_Anthropometry total_body_water_kg="[50.75-53.62]" } 20==>\text { AKTI_RAW } \\
\text { Number_of_awakenings_per_night_>_10_min="[-inf-0.45]" } 11 \text { conf:(0.55) }<\text { lift:(2.22) }>\end{array}$ \\
\hline 5. & $\begin{array}{l}\text { AKTI_IND Average_length_of_sleep="(-inf-3.1]" } 21==>\text { PSYCHO Self-evaluation Independence= "(8.6-9.3]" } 11 \text { conf:(0.52) } \\
<\text { lift:(2.2)> }\end{array}$ \\
\hline
\end{tabular}

\section{Conclusion and discussion}

The purpose of this study was to examine the most useful methods and feature extraction algorithms that effectively reflect the physical and mental health of Czech Armed Forces. Since the workload and work schedule can vary among military units, we chose two specific groups that have very different duties and organizational planning. The differences between these units can be seen in the results, where the features for Castle Guard group had the most significant associations in median wake time and vitality. Self-evaluated vitality is also connected to the continuity of sleep. There are more sleep relevant features, like continuity of sleep and self-perceived independence or sleep efficiency and appearance. The paratrooper unit had slightly different results more closely related to biological markers, although sleep plays a role in health and work success as well. The work success rate is associated with good cognitive ability focused on visuo-spatial short-term working memory as measured by the Corsi test. Professional success is also related to a low level of dispersion of sleep efficiency, which means that the person usually gets the same effective sleep over the 14-day measurement period. Other significant biological associations were found, such as low percentage of awakenings and higher basal metabolism together with higher total body water. The more continuous sleep the person gets the better basal metabolism he has together with a healthier water ratio in the body.

The results indicate that health and work efficiency is mostly reflected by sleep related features. Given the analysis of the 118 features extracted from various fields and commonly used methods to determine military personnel vitality, fatigue, work success and overload, the sleep related features demonstrated the most relevant associations. To make conclusions for the military environment as a whole, it is necessary to differentiate between units, their working schedule and their mental and physical demands, so we cannot expect these results to be applied uniformly to all military personnel. Giving these findings, the goal of a new research might consider potential ways to measure various military units. Still, our results indicate a clear need for discussing and ensuring better sleep hygiene practices, which are often routinely disregarded during operational planning.

\section{References}

Anderson, T., Lane, A. R., \& Hackney, A. C. (2016). Cortisol and testosterone dynamics following exhaustive endurance exercise. European journal of applied physiology, 116(8), 1503-1509.

Askling, C., Karlsson, J., \& Thorstensson, A. (2003). Hamstring injury occurrence in elite soccer players after preseason strength training with eccentric overload. Scandinavian journal of medicine \& science in sports, 13(4), 244-250.

Basta, M., Chrousos, G. P., Vela-Bueno, A., \& Vgontzas, A. N. (2007). Chronic insomnia and the stress system. Sleep medicine clinics, 2(2), 279-291.

Bonnet, M. H., \& Arand, D. L. (2010). Hyperarousal and insomnia: state of the science. Sleep medicine reviews, 14(1), 9-15.

Costa Jr., Paul T., a Robert R. McCrae. „The Revised NEO Personality Inventory (NEO-PI-R)". In The SAGE handbook of personality theory and assessment, Vol 2: Personality measurement and testing, 179-98. Thousand Oaks, CA, US: Sage Publications, Inc, 2008.

Frank, E., Hall, M. A., and Witten, I. H. (2016). The WEKA Workbench. Online Appendix for Data Mining: Practical Machine Learning Tools and Techniques. Morgan Kaufmann, Fourth Edition.

Glienke, K., \& Piefke, M. (2017). Stress-related cortisol responsivity modulates prospective memory. Journal of neuroendocrinology, 29(12), e12544.

Hecksteden, A., Skorski, S., Schwindling, S., Hammes, D., Pfeiffer, M., Kellmann, M., ... \& Meyer, T. (2016). Blood-borne markers of fatigue in competitive athletes-results from simulated training camps. PloS one, 11(2), e0148810. 
Kang, S. R., Jung, G. Y., Moon, D. A., Jeong, J. S., Kim, J. J., \& Kwon, T. K. (2011). Evaluation of Bio-Mechanical Characteristics According to Loading Deviation Methods during Rowing Exercise. Korean Journal of Sport Biomechanics, 21(3), 369-382.

Kaplan, Z., Weiser, M., Reichenberg, A., Rabinowitz, J., Caspi, A., Bodner, E., \& Zohar, J. (2002). Motivation to serve in the military influence's vulnerability to future posttraumatic stress disorder. Psychiatry Research, 109(1), 45-49.

Larsson, H., Tegern, M., \& Harms-Ringdahl, K. (2012). Influence of the implementation of a comprehensive intervention programme on premature discharge outcomes from military training. Work, 42(2), 241-251.

Lewin, K., T. Dembo, L. Festinger, a P. S. Sears. „Level of aspiration". In Personality and the behavior disorders, 333-78. Oxford, England: Ronald Press, 1944.

LoPresti, M. L., Anderson, J. A., Saboe, K. N., McGurk, D. L., Balkin, T. J., \& Sipos, M. L. (2016). The impact of insufficient sleep on combat mission performance. Military Behavioral Health, 4(4), 356-363

Lüllmann, H., Mohr, K., \& Wehling, M. (2004). Farmakologie a toxikologie: 47 tabulek. GRADA Publishing as.

Malmberg, J. (2011). Physical fitness tests in the Nordic Armed Forces-A description of Basic Test Protocol.

Marsaglia, G., Tsang, W. W., \& Wang, J. (2003). Evaluating Kolmogorov's distribution. Journal of Statistical Software, 8(18), 1-4.

McGill, S. M., Childs, A., \& Liebenson, C. (1999). Endurance times for low back stabilization exercises: clinical targets for testing and training from a normal database. Archives of physical medicine and rehabilitation, 80(8), 941-944.

Mougios, V. (2019). Exercise biochemistry. Human Kinetics Publishers.

Mysliwiec, V., Walter, R. J., Collen, J., \& Wesensten, N. (2016). Military Sleep Management: An Operational Imperative. US Army Medical Department Journal.

Nibbeling, N., Oudejans, R. R., Ubink, E. M., \& Daanen, H. A. (2014). The effects of anxiety and exercise-induced fatigue on shooting accuracy and cognitive performance in infantry soldiers. Ergonomics, 57(9), 1366-1379.

Nwafor, C., \& Adesuwa, A. (2014). Psychological Testing and Assessment in the Military. Practicum Psychologia, 4, 1-10.

Payne, W., \& Harvey, J. (2010). A framework for the design and development of physical employment tests and standards. Ergonomics, 53(7), 858-871.

Peterson, A. L., Goodie, J. L., Satterfield, W. A., \& Brim, W. L. (2008). Sleep disturbance during military deployment. Military medicine, 173(3), 230-235.

Pruiksma, K. E., \& Peterson, A. L. (2018). Sleep Disturbance During Military Deployment. In Sleep and Combat-Related Post Traumatic Stress Disorder (pp. 59-68). Springer, New York, NY.

Toblin, R. L., Riviere, L. A., Thomas, J. L., Adler, A. B., Kok, B. C., \& Hoge, C. W. (2012). Grief and physical health outcomes in US soldiers returning from combat. Journal of Affective Disorders, 136(3), 469-475.

Troxel, W. M., Shih, R. A., Pedersen, E. R., Geyer, L., Fisher, M. P., Griffin, B. A., ... \& Steinberg, P. S. (2015). Sleep in the military: Promoting healthy sleep among US service members. Rand health quarterly, 5(2).

Van Dongen, H. P. (2006). Shift work and inter-individual differences in sleep and sleepiness. Chronobiology International, 23(6), 1139-1147.

Viru, A. A., \& Viru, M. (2001). Biochemical monitoring of sport training: Human Kinetics. Champaign, IL.

Ramos, R. W., Arvelo, A. D. A., \& Gomez, J. P. (2013). Hyperarousal in insomnia. Sleep Medicine, 14, e240-e241.

Stoet, G. (2010). PsyToolkit: A software package for programming psychological experiments using Linux. Behavior Research Methods, 42(4), 1096-1104.

Stoet, G. (2017). PsyToolkit: A novel web-based method for running online questionnaires and reaction-time experiments. Teaching of Psychology, 44(1), 24-31.

Zammit, G. K., Weiner, J., Damato, N., Sillup, G. P., \& McMillan, C. A. (1999). Quality of life in people with insomnia. Sleep: Journal of Sleep Research \& Sleep Medicine. 